\title{
INTEGRAÇÃO DO ENSINO E SERVIÇO DE ENFERMAGEM COM A REDE HOSPITALAR GOVERNAMENTAL
}

\author{
Hyêda Maria Rigaud de Castro*
}

$\operatorname{RBEn} / 03$

CASTRo, H. M. R. - Integração do Ensino e Serviço de Enfermagem com a Rede Hospitalar governamental. Rev. Bras. Enf., Rio de Janeiro, 28: 28-36, 1975.

\section{CONSIDERAÇÕES GERAIS}

Desde há muito tempo, é ccnstante a nossa preocupação quanto à necessária objetividade do ensino, a fim de que, na prática, haja um melhor nível profissional, baseado naqueles ensinamentos recebidos nas Escolas.

$\mathrm{Na}$ proposição de integrar a rede hospitalar governamental, consideramos ser de grande valor a utilização desses campos pelas Escolas e que estas trigam uma filosofia de integração, de participação ativa e de cooperação mútua; então, pessoas alheias à burocracia governamental poderão ajudar na racionalização de processos administrativos em função de uma melhor assistência ao paciente.

As deficiências fundamentais encontradas quanto aos campos de estágios são devidas a:

- maior a procura que a oferta, nestes campos de estágio;

. número reduzido de serviços de enfermagem organizado;
- crescente aumento do número cie alunos para os mesmos campos de estágio.

Tudo isso nos levou a meditar sobre o assunto, e pareceu-nos feliz a oportunidade de apresentar este trabalho, pois, ao instalarmos e organizarmos o Serviço de Enfermagem da Coordenadoria de Assistência Hospitalar (CAH) da Secretaria de Estado da Saúde de São Paulo, foi nosso primeiro objetivo transformar ou implantar Serviços de Enfermagem em condições de oferecer campo de estágios às Escolas de Enfermagem.

Em consequência deste objetivo, outro se impôs: a implementação de recursos humanos, e especificamente, de enfermeiras(os), a fim de organizar, reorganizar ou implantar os Serviços de Enfermagem da rede hospitalar governamental.

Isto já está parcialmente atingido ccmo veremos a seguir, pois aumentou em $369 \%$, de 1971 a 1975 , o número de enfermeiras(os).

Por outro lado, o Plano Decenal de

* Diretora do Serviço de Enfermagem da Coordenadoria de Assistência Hospitalar da Secretaria de Estado da Saúde de São Paulo - SP. 
CASTRO, H. M. R. - Integração do Ensino e Serviço de Enfermagem com a Rede Hospitalar governamental. Rev. Bras. Enf., Rio de Janeiro, 28: 28-36, 1975.

Saúde para as Américas (1971-1980), elaborado na III Reunião de Ministros de Saúde, no Chile, em 1972, e, posteriormente, o XIX Congresso Sanitário Panamericano, através da Resolução XXVIII, estabelecendo as "metas para o Decênio em Enfermagem”, vieram fortalecer nossas metas, despertando as autoridades no sentido de estabelecer-se uma política claramente definida sobre a assistência de enfermagem e a formação de pessoal necessário nesta área

Isto posto, consideramos importante apresentar ante-projeto e minuta de Regulamento que venham dar uma situação de Lei ao que já existe de fato, os estágios em unidades hospitalares governamentais.

\section{OBJETIVOS}

- Verificar o que vem sendo feito, no sentido dos hospitais da rede governamental apresentarem as necessárias condições, como campos de estágio para enfermagem:

- encorajar a integração do ensino com a prática profissional, através da revisão dos objetivos de ambos;

- apresentar ante-projeto e minuta de regulamento como instrumento legal, a fim de estimularem-se aquelas Unidades que ainda não oferecem condições de dar melhor assistência ao paciente.

\section{PROBLEMAS}

(1) E constante a preocupação de integrar a prática com a teoria, nos cursos de enfermagem. Não obstante verificamos, ao receber o profissional recémformado, a falta de dimensão profissional. Exemplificaremos o exposto: grande a dificuldade que sentimos com os profissicnais que fazem anotações de enfermagem, e a resistência à implanta- ção do plano de assistência de enfermagem.

Durante o Seminário sobre integração de ensino e Serviço de Enfermagem em hospitais Universitários, realizado aqui em Salvador, em 1969, dizia o Prof. Roberto Santos: "O que importa é que o estudante não fique preso exclusivamente ao Hospital Universitário durante o seu período de formação, e que sua atividade extravaze até as unidades mais simples do sistema, onde tomará contacto mais direto com os problemas de saúde da comunidade, ainda sob a supervisão do pessoal docente da Universidade". Haveria, com isto, uma visão menos distorcida da realidade por parte dos profissionais recém-formados, favorecendo seu ajustamento, e não permitindo a omissão das responsabilidades inerentes à profissão.

(2) A superpopulação de alunos nos mesmos campos de estágio dificulta a possibilidade de aprendizagem integrada.

(3) Em setembro de 1971, a situação do número de Enfermeiras(os) nos Hospitais desta Coordenadoria era de carência de pessoal profissional. A seguir, mostraremos o quadro comparativo de 1971, 1973 e 1975, onde pode ser apreciado o sensível crescimento do pessoal profissional.

\section{METODOLOGIA}

Para chegar a constatar o que afirmamos, foram usados os seguintes métodos:

- entrevista com os Chefes de Serviços de Enfermagem, com o objetívo de verificar-se os hospitais que já ofereciam campos de estágio.

- levantamento de recursos humanos, 
CASTRO, H. M. R. - Integração do Ensino e Serviço de Enfermagem com a Rede Hospitalar governamental. Rev. Bras. Enf., Rio de Janeiro, 28: 28-36, 1975.

\section{SITUAÇÃO DO N. ${ }^{\circ}$ DE ENFERMEIROS NOS HOSPITAIS DA CAH NOS ANOS DE 1971-1973 e 1975}

Nome dos Hospitais

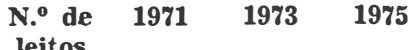

1. Hospital Emílio Ribas - Capital

2. Instituto de Cardiologia - Capital

3. Hospital Infantil Cândido Fontoura - Capital

4. Unidade Infantil da Moóca - Capital

5. Hospital Regional de Promissão - Capital

6. Hospital Geral de Mirandópolis - Mirandópolis

7. Hospital Infantil Zona Leste - Capital

8. Parque Hospital do Mandaquí - Capital

9. Hospital Nestor Goulart Reis - Américo Brasiliense

10. Hospital Clemente Ferreira - Lins

11. Hospital Adhemar de Barros - Divinolândia

12. Hospital Manoel de Abreu - Bauru

13. Hospital Guilherme Álvaro - Santos

14. Hospital Leonor Mendes de Barros - Sorocaba

15. Hospital Santo Ângelo - Mogi

17. Hospital Pirapitingui - Itu

18. Hospital Lauro de Souza Lima - Bauru

19. Hospital Adhemar de Barros - Guarulhos

20. Policlínica - Capital

21. Hospital Regional do Vale do Ribeira - Pariquera-Açu

22. Hospital Sta. Rita do Passa Quatro - Sta Rita do Passa Quatro

23. Hospital Padre Bento - Guarulhos

$\begin{array}{rrrr}400 & 10 & 41 & 49 \\ 91 & - & 21 & 29 \\ 200 & 6 & 19 & 22 \\ 80 & - & 6 & 6 \\ 85 & - & - & - \\ 125 & - & 2 & 1 \\ 223 & - & 20 & 26 \\ 545 & 10 & 10 & 21 \\ 504 & - & 1 & 1 \\ 504 & - & - & - \\ 233 & 1 & 1 & 1 \\ 170 & 1 & 1 & 1 \\ 166 & 1 & 5 & 15 \\ 148 & - & - & 13 \\ 300 & - & 4 & 3 \\ 700 & 2 & 6 & 3 \\ 500 & 2 & 2 & 2 \\ 75 & - & - & - \\ - & 2 & 2 & 2 \\ 180 & 2 & * & * \\ 1000 & 5 & * * & * * \\ 200 & 2 & 5 & 2 \\ & & & \end{array}$

TOTAL

* Passou a integrar o projeto Devale.

* Passou a integrar a Coordenadoria de Saúde Mental.

ou seja, de enfermeiras(os), nas Unidades da CAH.

- Referências bibliográficas.

De acordo com entrevistas com as Chefes dos Serviços de Enfermagem, pudemos verificar que sete dos hospitais governamentais desta Coordenadoria já oferecem campo de estágio. São eles:

- Instituto de Cardiologia - Capital

- Hospital Emílio Ribas - Capital

- Hospital Guilherme Álvaro - Santos

- Hospital Geral de Mirandópolis Mirandópolis
- Hospital Santo Ângelo - Mogi

. Hospital Pirapitingui - Itu

- Hospital Cândido Fontoura - Capital

Outros foram utilizados ou solicitados para visitas, mas não oferecem oportunidade de estágio, devido a não existência das condições mínimas necessárias.

Dos 20 hospitais que formavam, em 1971, a rede hospitalar governamental, dois foram criados posteriormente: o "Hospital Infantil Zona Norte" e a "Unidade da Moóca"; nestes só havia 42 enfermeiras, todas distribuídas em 11 
CASTRO, H. M. R. - Integração do Ensino e Serviço de Enfermagem com a Rede Hospitalar governamental. Rev. Bras. Enf., Rio de Janeiro, 28: 28-36, 1975.

unidades, sendo que 9 unidades não contavam com profissionais enfermei$\operatorname{ras}(\mathrm{os})$.

Em 1973, houve um acréscimo de $281 \%$; mesmo assim, 3 unidades permaneceram sem enfermeiras(os), tendo, 2 hospitais, passado a integrar outros projetos.

A presente situação (1975) não é ainda a ideal, pois não temos conseguido alcançar totalmente um dos nossos objetivos, isto é, a implementação de pessoal profissional necessário às condições de cada unidade hospitalar. Contudo, houve um crescimento de $369 \%$ sobre a situação encontrada em 1971 e de $23,12 \%$ de 1973 a 1975, mas 3 unidades ainda continuam sem pessoal profissional enfermeira (o).

Dando uma volta no tempo, procurando verificar como se tornaram campo de estágio os hospitais da rede governamental, podemos observar que certos hospitais ofereceram campos de estágio devido à causa fortuita de determinadas doenças (tais como a Hanseniase e as Doenças Transmissíveis) e a maioria dos Hospitais Psiquiátricos serem de controle estatal; nesta época, mesmo sem oferecerem condições, eram, estes os hospitais únicos em que os alunos poderiam conhecer aqueles pacientes. Hoje, não somente por estes motivos, mas com a finalidade de melhorar a assistência prestada, cada vez mais os hospitais se esforçam em aprimorar o padrão de qualidade a oferecer.

\section{METAS}

Consideramos que duas metas deverão ser atingidas urgentemente:

a) Revisar os objetivos comuns de formação profissional entre Escolas e Serviços de Enfermagem, funcionando estes como um sistema de "feed-back" para as Escolas.

b) Apresentar ante-projeto que disponha sobre a instituição do Regime de Estágio de Enfermagem nos Hospitais, Institutos Técnicos Científicos e Unidades Sanitárias da Secretaria de Estado da Saúde, e a minuta de Regulamento do Regime de Estágio.

\section{ANTE-PROJETO N. ${ }^{\circ}$, de de de 1975}

Dispõe sobre a instituição de Regime de Estágio de Enfermagem nos Hospitais, Institutos Técnicos-Científicos, Unidades Sanitárias da Secretaria de Estado da Saúde, e dá outras providências.

, Governador

do Estado de São Paulo no uso de suas atribuições legais.

Considerando que é dever co Estado fortalecer, apoiar e incentivar o ensino da enfermagem, visando à capacitação de recursos humanos no campo da saúde, para a formação e o aprimoramento profissional;

Considerando que os estágios, além dos ccnhecimentos que irão proporcionar, virão a prestar relevantes serviços à assistência de enfermagem;

Considerando que o ensino da enfermagem deve proporcionar ao estudante a compreensão da realidade sanitária e sócio-econômica indispensável ao exercício de sua atividade profissional;

Considerando que a articulação dos Serviços de Saúde com as Escolas de Enfermagem abre uma nova perspectiva na expansão do campo docente assistencial, criando benefícios para o ensino, para as organizações de saúde e para a comunidade que deles se utiliza;

Considerando a necessidade da interiorização regional progressiva dos Serviços de Saúde, através de uma organização básica para a expansão das atividades da medicina preventiva e curativa, especialmente em proveito dos pequenos núcleos populacionais; 
CASTRO, H. M. R. - Integração do Ensino e Serviço de Enfermagem com a Rede Hospitalar governamental. Rev. Bras. Enf., Rio de Janeiro, 28: 28-36, 1975.

Considerando que esses objetivos estão consubstanciados nas conclusões e recomendações do Plano Decenal de Saúde para as Américas, aprovado por unanimidade por todos os países do continente, inclusive o Brasil, na III Reunião dos Ministros da Saúde, realizada em 1972 e pertencente à Resolução n. ${ }^{\circ}$ XXVIII, que fixa as metas para o Decênio em Enfermagem da XIX Conferência Sanitária Panamericana realizada em Washington, de 30 de setembro a 10 de outubro de 1974;

Decreta:

Artigo $10^{\circ}$ - Fica instituído, nos Hospitais, Institutos Técnico-Científicos e Unidades Sanitárias da Secretaria da Saúde, o Regime de Estágio para estudantes e diplomados das Escolas de Enfermagem do País e do Estrangeiro.

Artigo $2 .^{\circ}-$ Os estágios classificamse em:
A) Graduação
B) Residência
C) Adidos.

Artigo $3 .^{\circ}$ - Graduação - são alunos do curso normal até as diversificações estabelecidas em lei, no último ano do referido curso.

Artigo $4 .^{\circ}$ - Residentes - são eı ${ }^{\circ} \mathrm{er}$ meiras(os) que completam e especiolizam seus conhecimentos, em regime de dedicação plena e exclusiva, com bolsa concedida pela Secretaria da Saúde.

Artigo $50^{\circ}$ - Adidos - são enfermei ras(os) que se aperfeiçoam em áreas definidas, voluntariamente, ou com bolsas outorgadas por órgãos governamentais, ou por outras entidades.

Artigo $60^{\circ}$ - As Escolas de Enfermagem convenientes concederão aos membros dos Hospitais, Institutos e Divisões Regionais da Secretaria da Saúde, os titulos universitários correspondentes às funções didáticas que vierem a exercer, respeitada a legislação vigente.
Artigo $70^{\circ}$ - O estágio de Residente será realizado por um período de 1 (um) ano, e poderá ser prolongado por mais um.

Artigo 8. - A estagiária (o) residente que tiver conseguido, ao término do período regulamentar, aproveitamento superior, será conferido um certificado que valerá como título especial em concurso para provimento de cargo específico do Estado.

Artigo $90^{\circ}$ - O número e o valor das bolsas concedidas pela Secretaria da Saúde serão fixados para o ano seguinte, até 0 dia 31 de março de cada ano.

Artigo $100^{\circ}$ - A admissão de enfermeiras(os) estagiárias(os) processar-seá mediante seleção de títulos e provas.

Artigo $11 .^{\circ}$ - As atribuições, os direitos e deveres das estagiárias (os), o relacionamento da Secretaria da Saúde com as Escolas de Enfermagem, assim como as demais questões conexas, serão estabelecidas mediante um Regulamento a ser baixado por aquele órgão, em 60 (sessenta) dias, contados da data de publicação deste Decreto.

Artigo $12 .^{\circ}$ - Dentro das características e capacidade de seus estabelecimentos, a Secretaria da Saúde poderá fornecer alimentação e alojamento às (aos) estagiárias(os).

Artigo $13 .^{\circ}$ - O estágio em Unidades Sanitárias será realizado prioritariamente nos Municípios cuja Prefeitura e outros órgãos estaduais ou federais contribuam com recursos financeiros para a realização integrada do serviço.

Artigo $14 .^{\circ}$ - As despesas com a execução do presente decreto correrão por conta dos recursos orçamentários da Secretaria da Saúde.

Artigo $15 .^{\circ}$ - Este decreto entrará em vigor na data de sua publicação, revogadas as disposições em contrário.

Palácio dos Bandeirantes, 
CASTRO, H. M. R. - Integração do Ensino e Serviço de Enfermagem com a Rede Hospitalar governamental. Rev. Bras. Enf., Rio de Janeiro, 28: 28-36, 1975.

\section{MINUTA}

Regulamento do Regime de Estágio de Enfermeiras(os) nos Hospitais, Institutos Técnico-Científicos e Unidades Sanitárias da Secretaria de Estado da Saúde.

\section{Capítulo I}

\section{Das Finalidades}

Artigo $1^{\circ}$ - O Regime de Estágio de Enfermeiras(os), instituído pelo Decreto n. ${ }^{\circ}$ de de de 19 , nos Hospitais, Institutos Técnico-Científicos e Unidades Sanitárias da Secretaria da Saúde, doravante chamados Unidades, reger-se-á pelas disposições constantes deste Regulamento.

Artigo 2. ${ }^{\circ}-$ Constituem objetivos principais do Regime de Estágio de Enfermeiras(os) a formação e o aprimoramento profissional, a prestação integralizada de serviços de saúde à Comunidade e a colaboração ao Ensino da Enfermagem.

\section{Capítulo II}

\section{Das Estagiárias(os)}

Artigo $3 .^{\circ}-$ As(os) estagiárias(os) classificam-se em:
A) Graduação
B) Residentes
C) Adidos.

Artigo $4^{\circ}$ - Graduação - são alunos, do curso normal até as diversificações estabelecidas em lei, no último ano do referido curso, que colaboram nos trabalhos, em complementação de um aprendizado pela prática e treinamento específico.

Artigo $50^{\circ}$ - Residentes - são enfermeiras(os) que completam e especializam seus conhecimentos, em regime de dedicação plena e exclusiva, com bolsas concedidas pelas Secretarias da Saúde ou outras unidades.

Artigo $60^{\circ}$ - Adidos - são enfermeiras(os) que se aperfeiçoam em áreas definidas, voluntariamente ou com bolsas concedidas por órgãos governamentais ou outras entidades.

Artigo 7..$^{\circ}$ Os Estagiários subordinam-se técnica, administrativa e disciplinarmente às Unidades onde forem servir, sujeitando-se aos seus Regulamentos, Regimentos e Normas.

Parágrafo Único - A orientação técnica dos estagiários deverá, nos dois primeiros casos, ser exercida pelas Escolas de Enfermagem, nos termos de convênios firmados com a Secretaria da Saúde.

Artigo $8 .^{\circ}$ - As Unidades estabelecerão, em Regimento Interno, a forma de admissão, as atribuições, os direitos e deveres dos estagiários, as disposições do presente Regulamento, e a legislação vigente.

\section{Capítulo III}

\section{Dos Estagiárics de Graduação}

Artigo $90^{\circ}$ - Os estagiários de Graduação terão suas atividades definidas em Convênios estabelecidos entre a Secretaria da Saúde e as Escolas de Enfermagem.

Artigo $100^{\circ}$ - A avaliação será feita de acordo com os regimentos das pastas a que estão subordinados.

\section{Capítulo IV}

\section{Das (os) Estagiárias(os) Residentes}

Artigo $11 .^{\circ}$ - Podem candidatar-se a residentes os formados por qualquer Escola do País ou do Estrangeiro, oficialmente reconhecida, possuidores de diplomas de conclusão do curso. 
CASTRO, H. M. R. - Integração do Ensino e Serviço de Enfermagem com a Rede Hospitalar governamental. Rev. Bras. Enf., Rio de Janeiro, 28: 28-36, 1975.

Artigo $12 .^{\circ}$ - A admissão dos residentes far-se-á mediante avaliação de títulos, e seleção por entrevistas e provas realizadas pelas Unidades.

Artigo $13 .^{\circ}$ - O estágio terá a duraçāo de 1 a 2 anos, distribuídos seus integrantes nas categorias R1 e R2, correspondentes ao primeiro e segundo ano de residência.

Artigo $14 .^{\circ}$ - Cada Unidade ou grupo de Unidades fará, de acordo com sua categorização assistencial ou técnicocientífica, a programação da residência.

Artigo $15 .^{\circ}-\mathrm{Em}$ toda programação de Residência será obrigatório o estágio em órgão de Divisões Regionais da Saúde da Capital ou do Interior, bem como a participação em atividades de Saúde Pública em cuidados específicos.

Artigo 16. - As (os) Residentes terão direito a 4 (quatro) semanas de férias, anualmente.

\section{Capítulo v}

Dos Adidos

Artigo $17 .^{\circ}$ - Os Adidos serão admitidos por avaliação de títulos e entrevistas.

Artigo $18^{\circ}$ - O estágio dos Adidos terá a duração de 3 (três) meses a 1 (um) ano.

Artigo $190^{\circ}-\mathrm{O}$ número de Adidos será fixado, atendendo-se à prioridade dos Residentes, aos programas de ensino e treinamento e às atividades assistenciais das Unidades.

Artigo $200^{\circ}$ - As atribuições e funções dos Adidos serão estabelecidas pelas Unidades e supervisionadas por seus Diretores.

\section{Capítulo VI}

Da Comissão do Estágio de Enfermeiras(os)

Artigo 21. ${ }^{\circ}$ - O Regime de Estágio de Enfermeiras(os) será supervisionado por
Comissão Permanente, que se denominará Comissão de Estágio de Enfermeiras(os) - CEEn, diretamente subordinada ao Gabinete do Secretário da Saúde.

Artigo 22..$^{\circ}$ - A CEEn será constituída por 6 (seis) membros, designados pelo Secretário da Saúde, a saber:

1. o Representante do Secretário da Saúde, que será o Presidente;

2. o Representante do Departamento T'écnico da Administração Superior da Secretaria da Saúde;

3. um Representante, Enfermeira (o) de cada uma das Coordenadorias da Secretaria da Saúde: Saúde da Comunidade, Assistência Hospitalar, Saúde Mental e Serviços Técnicos Especializados.

Artigo 23. - As decisões da CEEn serão tomadas por voto majoritário, presentes a maioria de seus membros, tendo o Presidente o voto de qualidade.

Artigo $24 .^{\circ}-\mathrm{O}$ mandato dos membros da CEEn será de 1 (um) ano, podendo ser renovado.

Artigo $25 .^{\circ}$ - Compete à CEEn:

1 - Aprovar os programas de estágios propostos pelas Unidades.

2 - Propor, com anuência das Unidades, o número e o valor das bolsas a serem concedidas anualmente aos Residentes pela Secretaria da Saúde.

3 - Decidir, em grau de recurso, sobre penalidades aplicadas aos estagiários pelos Diretores das Unidades.

4 - Decidir sobre proposta de cancelamento de estágios.

5 - Elaborar, de comum acordo com as Escolas de Enfermagem, Planos de Operação sobre os estágios, visando à regionalização de um sistema docenteassistencial dos Serviços de Saúde.

6 - Processar entendimentos com as Prefeituras e outros órgãos federais e estaduais, para a captação de recursos financeiros a serem empregados na realização integralizada dos Serviços de Saúde. 
CASTRO, H. M. R. - Integração do Ensino e Serviço de Enfermagem com a Rede Hospitalar governamental. Rev. Bras. Enf., Rio de Janeiro, 28: 28-36, 1975.

7 - Opinar sobre os Convênios a serem firmados com as Escolas de Enfermagem.

8 - Referendar os certificados de conclusão de estágios expedidos pelas Unidades.

9 - Aprovar o seu Regimento Interno.

10 - Conceder afastamento aos Estagiários, quando por período superior a 60 (sessenta) dias, por doença ou motivo excepcional.

11 - Propor alterações ao presente Regulamento.

12 - Deliberar sobre casos omissos ou não, previstos neste Regulamento.

Artigo 26..$^{\circ}$ - Ao Presidente da CEEn compete:

$1 .^{\circ}$ - Convocar e presidir suas reuniões.

2. - Fazer cumprir o presente Regulamento e as deliberações da CEEn.

\section{Capítulo VII}

Das Bolsas

Artigo 27..$^{\circ}$ - O número e o valor das bolsas concedidas pela Secretaria da Saúde serão estabelecidos especificamente para cada Unidade, para o ano seguinte, até 31 de março de cada ano.

Artigo $28^{\circ}$ - Os valores correspondentes às bolsas serão reajustados em bases idênticas às dos eventuais aumentos de vencimentos outorgados ao funcionalismo público estadual.

\section{Capítulo VIII}

\section{Dos Afastamentos}

Artigo 29. - Os Diretores das Unidades poderão autorizar afastamentos dos Estagiários para comparecimento a cursos, reuniões científicas e estágios em outras instituições por prazo não superior a 60 (sessenta) dias.
Artigo $300^{\circ}-$ Os afastamentos por doença ou motivos excepcionais até 60 (sessenta) dias, poderão ser concedidos pelos Diretores das Unidades.

\section{Capítulo IX}

\section{Das Penaliciades}

Artigo 31..$^{\circ}$ Os Estagiários que cometerem infração ao presente Regulamento e que venham violar a disciplina da Unidade ou infringir o Código de Ética de Enfermagem, estão sujeitos às seguintes penalidades, de acordo com a natureza e gravidade da falta cometida:
A) Advertência
B) Repreensão
C) Cancelamento do estágio.

\$ $10^{\circ}$ - As penalidades de advertência e suspensão serão impostas pelos Diretores das Unidades.

$\S 2 .^{\circ}$ - O cancelamento do estágio será aplicado pela CEEn, por proposta fundamentada dos Diretores das Unidades.

\section{Capítulo $\mathbf{X}$}

\section{Das Disposições Finais}

Artigo $32 .^{\circ}$ - Aos Estagiários que, ao cabo do tempo regulamentar do estágio, houverem revelado real aproveitamento e dedicação ao serviço, as Unidades expedirão certificado, referendado pela CEEn, que valerá como título especial em concurso para provimento de cargo específico do Estado.

Artigo 33..$^{\circ}$ - Dentro das características e capacidade de seus estabelecimentos, a Secretaria da Saúde poderá fornecer alimentação e alojamento aos Estagiários.

Parágrafo Único - As Unidades poderão estabelecer taxas relativas ao fornecimento de alimentação e alojamento. 
CASTRO, H. M. R. - Integração do Ensino e Serviço de Enfermagem com a Rede Hospitalar governamental. Rev. Bras. Enf., Rio de Janeiro, 28: 28-36, 1975.

Artigo $34 .^{\circ}$ - A admissão ao Regime de Estágio de Enfermeira(o) não cria qualquer vínculo empregatício ou relação estatutárias entre o Estagiário e o Foder Público.

Artigo $35^{\circ}$ - A Secretaria da Saúde colocará, à disposição da CEEn, o pessoal necessário ao exercício de suas atividades.

\section{Capítulo XI}

Das Disposições Transitórias

Artigo $10^{\circ}$ - Para cada exercício será fixadio o número de bolsas de Residentes e Unidaces a que serão destinados, publicados em Diário Oficial.

Artigo 2. ${ }^{\circ}$ - Os valores correspondentes às bolsas serāo fixados para cad.a exercício com publicação em Diário Oficial.

Parágrafo Único - As bolsas para Adidos serão propostas pelos Diretores das Unidades.

Artigo $3 .^{\circ}$ - Ao Secretário da Saúde caberá, por proposta da CEEn, estabelecer as Unidades que estão em condições de desenvolver as referidas programações.

\section{CONCLUSÕES}

- A integração do ensino teórico com o trabalho prático e complementado com pesquisas resultará numa conscientização e solução dos problemas da área de assistência de enfermagem;

- a integração favorece a participação de tođos os elementos que fazem parte do sistema (ou subsistema), assim contribuindo para melhorar os processos técnicos administrativos;

- os elos ligando os serviços de enfermagem, ensino e pesquisa deverão ser colocados tanto em nível normativo quanto executivo, a fim de permitir a necessária coordenação;

- rom o estabelecimento da lei, a Universidade deverá outorgar títulos àqueles que se distinguirem no adestramento dos estagiários.

\section{RECOMENDAÇÕES}

Que seja feita a reavaliação dos objetivos comuns entre Escolas e Campos de Estágio, com o propósito de um melhor rendimento profissional.

Que seja criada lei que regulamente o estágio de enfermagem na rede hospitalar governamental.

\section{REFERENCIAS BIBLIOGRÁFICAS}

(1) LAWRENCE \& LORSCH - O desenvolvimento da Organização: Diagnóstico e Ação (Tradução do Pret. Mexer Silman), São Paulo Brasil, 1972.

(2) Seminário Sobre Integração de Ensino e Serviço de Enfermagem em Hospitais Universitários - Salva¿or - BA, Brasil, 1969.

(3) Educacion Médica y Salud - Orga- nizacion Panamericana de La Salud, Volume 7, Números 3-4, 1973.

(4) RIGAUD DE CASTRO, H. M. e colaboradores - Organização de um Serviço de Enfermagem em Nível Central. Rev. Bras. Enf.; Rio de Janeiro, 26(6): 482-500, 1973.

(5) Decretos e Regulamentos referentes à matéria. 